\title{
Erratum to: Surgical treatment of peroneal nerve palsy after knee dislocation
}

\author{
Steven A. Giuseffi • Allen T. Bishop • \\ Alexander Y. Shin - Diane L. Dahm • \\ Michael J. Stuart $\cdot$ Bruce A. Levy
}

Published online: 15 September 2010

(C) Springer-Verlag 2010

Erratum to: Knee Surg Sports Traumatol Arthrosc

DOI 10.1007/s00167-010-1204-3

Unfortunately, the order of the authors had been given incorrectly in our article. The correct order of authors should read: Steven A. Giuseffi, Allen T. Bishop, Alexander Y. Shin, Diane L. Dahm, Michael J. Stuart, Bruce A. Levy as now given above and below.

The online version of the original article can be found under doi: 10.1007/s00167-010-1204-3.

\footnotetext{
S. A. Giuseffi - A. T. Bishop · A. Y. Shin ·

D. L. Dahm · M. J. Stuart · B. A. Levy $(\bowtie)$

Department of Orthopaedic Surgery, Mayo Clinic,

200 First Street SW, Rochester, MN 55905, USA

e-mail: Levy.Bruce@mayo.edu
} 